\title{
Two Mechanisms of Rejuvenation Using Thread Lifting
}

\author{
Mototsugu Fukaya, MD
}

T here exist 2 mechanisms underlying the effect of thread lifting that surgeons should be aware of. One mechanism exhibits a purely mechanical effect of lifting as shown in the experiment using chicken and chicken skin (Figs. 1, 2). This mechanism involves the distribution of the gravity load to the surrounding areas via a thread. A long-term effect can be expected if the thread is insoluble and accurately inserted. ${ }^{1}$ The other mechanism involves the fibrosis of the surrounding tissue due to the inserted thread, which acts as a foreign body. Regardless of the type of thread material, fibrosis may occur. A similar long-term effect is also observed for soluble threads such as polydioxanone. However, such an effect ameliorates the tenseness of the skin by increasing the amount of subcutaneous fibrous tissue, which is too weak to suspend sagging.

Soluble threads begin hydrolyzing even following contact with air by moisture absorption. Therefore, such threads are packed in an aluminum-coated damp-proof bag. After hydrolyzation, the thread becomes very fragile and loses its ability to mechanically lift the skin because it breaks even before being totally absorbed.

The disadvantages of soluble threads are that a longterm effect cannot be expected and that they cannot be removed in case of a problem, such as an infection. If the thread is made from a strong, insoluble material without any broken part, it can be completely removed by locating and carefully pulling its end. However, because a soluble thread becomes fragile within the tissue, it breaks easily when pulled out. The remnant parts remain in the deep tissue until they are totally absorbed, which can cause delayed infection. As both soluble and insoluble threads are the same in the sense of foreign body in the tissue, the risk of infection is not considered to be different. Accordingly, the risk of infection associated with soluble threads is higher than that with insoluble threads. Moreover, soluble polymers sometimes cause allergies in vivo. ${ }^{2,3}$

Although many surgeons may assume that soluble threads are safer than insoluble threads as viewed through images, the author suggests reconsideration.

\section{Mototsugu Fukaya, MD \\ Tsurumai Kouen Clinic 5-20-6 Chiyoda Nakaku Nagoya 4600012 Japan}

From the Tsurumai Kouen Clinic, Nagoya, Japan.

Copyright @ 2018 The Author. Published by Wolters Kluwer Health, Inc. on behalf of The American Society of Plastic Surgeons. This is an open-access article distributed under the terms of the Creative Commons Attribution-Non Commercial-No Derivatives License 4.0 $(C C B Y-N C-N D)$, where it is permissible to download and share the work provided it is properly cited. The work cannot be changed in any way or used commercially without permission from the journal. Plast Reconstr Surg Glob Open 2018;6:e2068; doi:10.1097/ GOX.0000000000002068; Published online 14 December 2018.

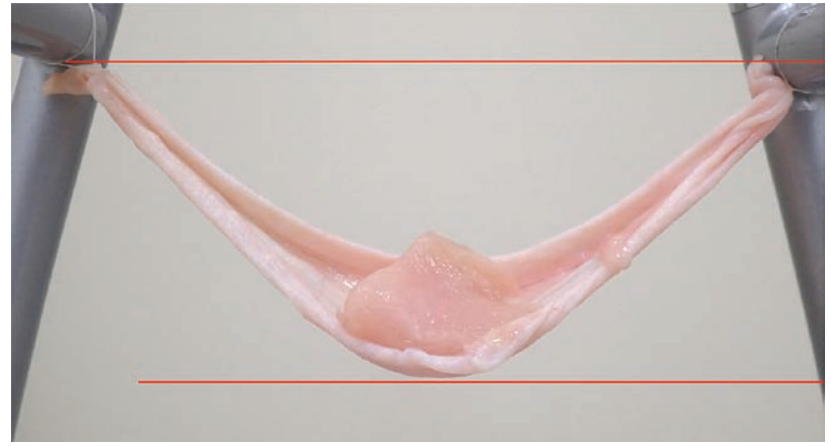

Fig. 1. A model of sagged cheek using chicken and chicken skin. Before insertion of a thread. Red baseline is included for clarifying the degree of lifting.

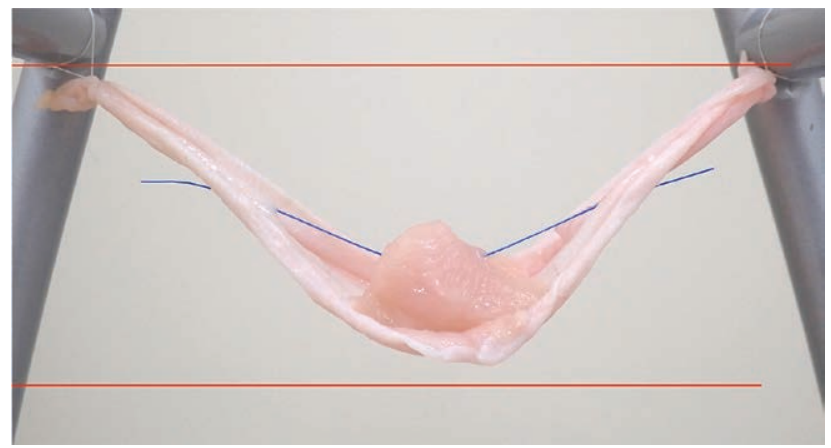

Fig. 2. After a thread has been inserted. Red baseline is included for clarifying the degree of lifting.

\section{DISCLOSURE:}

The author has no financial interest to declare in relation to the content of this article. The Article Processing Charge was paid for by the author.

\section{REFERENCES}

1. Fukaya M. Long-term effect of the insoluble thread-lifting technique. Clin Cosmet Investig Dermatol. 2017;10:483-491.

2. Della Torre F, Della Torre E, Di Berardino F. Side effects from polydioxanone. Eur Ann Allergy Clin Immunol. 2005;37:47-48.

3. Guardiani E, Davison SP. Angioedema after treatment with injectable poly-L-lactic acid (Sculptra). Plast Reconstr Surg. 2012;129:187e-189e. 